\title{
Syntactic Constructions Featuring Multifunctional Sentence Components in the Language of Modern Business Media
}

\author{
Elena Malyuga ${ }^{1}$, Nataliia Poliakova ${ }^{1} \&$ Barry Tomalin $^{2}$ \\ ${ }^{1}$ Peoples' Friendship University of Russia (RUDN University), Moscow, Russian \\ ${ }^{2}$ UCL, London, United Kingdom \\ Correspondence: Elena Malyuga, Head of Foreign Languages Department, Faculty of Economics, Peoples' \\ Friendship University of Russia (RUDN University), 117198, Miklukho-Maklaya str.6, Moscow, Russian. \\ E-mail: davidwolf@ncu.ca
}

Received: April 22, 2019 Accepted: May 20, 2019 Online Published: June 27, 2019

doi:10.5539/ijel.v9n4p58 URL: https://doi.org/10.5539/ijel.v9n4p58

\begin{abstract}
The paper summarises research findings concerned with the study of functional and cognitive properties of multifunctional sentence components used in the framework of business communication, as well as their actualisation in the context of the speaker's linguistic identity. While such components appear understudied, they largely shape the linguacultural profile of a given language. Therefore, a study promoting accurate perception of their properties may lay the ground for a better and more productive intercultural business interaction. The study considers language units functioning at different levels in English, French and Russian to single out the types and functions of syntactic relationships registered in these languages, as well as the means of their expression. The study shows that as far as syntactic constructions featuring multifunctional coordinating components are concerned, their specifics is manifested not only in the set of coordinating means, but also in the peculiarities of their functioning.
\end{abstract}

Keywords: business communication, coordinating conjunction, multifunctional components, functional syntax, linguistic identity

\section{Introduction}

\subsection{Coordinating Constructions in Professional Communication}

Modern linguistic science demonstrates the increased interest towards the various kinds of coordinating constructions, which is due to the active development of such new lines of research as logical linguistic analysis and semantic syntax. A major driving force behind the expansion of multifunctional constructions studies has to do with the evident amplification of the functional trend, which can be instrumental in describing practical manifestation of a phenomenon actualised within a given language. With this type of constructions, the problem is that the connections within them diverge from traditional standards of composition, which warrants the emergence of unique original features in speech or text. These features, in turn, take shape as linguistic identity is developed and actualised in speech practices. Notably, in studying syntactic coordination, researchers mostly address coordinating conjunctions, which are the main means of expressing coordination and a central (core) element of sentence structure.

In the context of multiculturalism, peoples' linguistic identities are obviously inseparable from their cultural identities: according to the well-known expert in language and culture relationships David Crystal, "it is virtually impossible for people to engage with speakers of other languages in everyday conversation without cultural issues needing to be taken into account" (Crystal, 2017, p. 16). This paper aims to study the relationship between opposing identities in the process of professional communication as one of the key instruments of intercultural interaction. The authors argue that a valuable step in addressing the stated agenda lies in studying syntactic constructions featuring multifunctional coordinating components (CMCCs). The language of business media was used as a productive source of material to investigate English, French and Russian syntactic constructions and the corresponding implications for identity research.

The study intends to develop a set of indicators to be used in measuring the relationship between professional language and identity, investigating the connection between language and identity, and examining the correlation 
of personal vs social and/or cultural group identity. The authors also consider national and cultural hallmarks of language units functioning at different levels in English, French and Russian, and analyse the types and functions of syntactic relationships registered in these languages, as well as the means of their expression.

\subsection{Professional Language and Identity}

Identity is a multivalent concept, which is perceived and interpreted differently within various domains of research. Broadly speaking, the key to understanding the concept of identity lies in differentiating personal and social identities, which are contrasted as a set of features distinguishing one individual from another (personal), and the set of features acquired as a result of community or group belonging (social). While language and culture are indisputably connected, cultural identity exhibits its specific peculiarities and has a lot in common with the notions of social and ethnic identity.

Language represents one of the key indicators of identity. Linguistic identity is associated with language groups a person belongs to, as well as with a person's self-identification with the corresponding culture. A linguaculture unites people, creating a shared identity for the members of a single community, which is why linguacultural identity implies linguistic uniformity of a people (Vishnyakova \& Polyakova, 2017). People's linguistic identities may change throughout their lifetime for different reasons, including the existence of the so called 'contact zones' ("points where different languages and cultures meet") (Aleksandrova, Mendzheritskaya, \& Malakhova, 2017, p. 100). Therefore, various aspects of human activity need to be considered in investigating this issue - including the role of professional activity in the evolution of linguistic identity.

The advent of globalisation implies extension of relationships and interdependencies of different languages and cultures in the context of business and professional communication. Global changes in linguistic and cultural trends also translate into cultural disunity, prompting some nations to strive for cultural self-assertion and preservation of their traditional values. In this context, CMCCs provide valuable material the can be studied to better describe the issues of contemporary professional language and linguistic identity.

Structurally, a business person's professional identity comprises three levels: the verbal-semantic level (acquiring professional speech, terminology, jargon, the thematic context emerging in the framework of professional activity); the thesaurus level (acquiring professional mentality determined by the specifics of professional activity and reflected in speech activity and the peculiarities of speech perception; at this level of professional identity, a business person establishes the sphere of concepts with "business" as its core concept); the motivational level (reflects the set of professional values, motives, beliefs, intentions that are realised through specific speech strategies).

A professional linguaculture is not traditionally viewed as an independent type, because professional linguacultures are studied as branches of culture or as subcultures that include speech etiquette, traditions, customs, etc. These components are a set of social norms of conduct.

The increased attention towards the professional language can be attributed to the growing multiculturalism and the spreading business communication practices, whereby the issue of efficient interaction is brought to the forefront (Malyuga \& Tomalin, 2017; Ponomarenko, 2018). Linguacultural and functional-cognitive premises of text organisation vary widely in different languages and call for scientific consideration mainly because of their inseparable association with cultural uniqueness. From this perspective, a study of functional-semantic and structural-semantic aspects of CMCCs may shed light on the specifics of people's cognitive and linguistic perceptions and behaviour.

Professional language is a historical and national category, a product of various factors and their intertwined synergies. Linguists emphasise the key role of social factors in the process of language development (Bradley \& Bradley, 2013; Bright, 2017; Gregory \& Carroll, 2018; Roberts \& Winters, 2012). The expansion of economic and political relations is also one of the building blocks for social integration.

This study is primarily concerned with the role of language in identity development, as well as with the interconnection between national language and identity. Considering the connection between language and identity, their integration can be viewed not only as a generalisation of social and spiritual experience, but also as a collective reflection. The objects of the world and their signs are not always named exactly, with the help of names, in the meaning of which the stereotypical idea of the language speakers about the named object is fixed. The vagueness of perception and identification, the ambiguity of the attitude, the absence of the name of the object in the speaker's language or its rejection can lead to certain nomination difficulties, which makes it necessary to resort to means of approximate nomination (McGee, 2018). In intercultural professional and business communication, identity is the basis for national and cultural identity, an indicator of one's own and the 
opposite of a stranger. Consequently, intercultural business and professional communication can be viewed as a relationship of opposing identities, forming a foundation for business partners' communication.

\section{Theoretical Background}

In the public eye, profession acts as a model of a specific lifestyle and a source shaping a person's crucial values and beliefs. In its linguistic actualisation, professional knowledge helps perceive and explain the surrounding realia, which is why a detailed and multifaceted study of professional language, and particularly its understudied syntactical issues, will contribute to a deeper understanding of the various processes taking place in the contemporary language of business communication.

CMCCs have been garnering linguists' attention for a while now. They were first registered in the French language by Antoine (Antoine, 1962), who described them using the term "constructions différées". Constructions featuring coordinating components are syntactic constructions where a coordinating conjunction unites words fulfilling various syntactic functions. For example:

(1)

$\begin{array}{llll}\text { Les } & \text { profits } & \text { sont } & \text { en hausse, } \\ \text { The profits } & \text { are } & \text { in rise, }\end{array}$

'The profits are up, but at what price?' (Smith, 2018)

There might be a housing crisis— but not in my back yard (Derounian, 2013).

However, the status of CMCCs remains a disputable issue. Most of the studies only offer brief accounts of this type of syntactic constructions with no theoretical backing or interpretation whatsoever.

A comprehensive investigation of CMCCs can be found in the work by Haff (Haff, 1990). In her monograph, the author relies on the functional approach towards syntactic coordination, offers an exhaustive analysis of the functions of coordinating conjunctions and catalogues coordinating word classes in contemporary French to conclude that consistent occurrence of CMCCs and their recurrent use attest to their prevalence, as well as their "legitimacy".

Even a cursory review of theoretical studies concerned with CMCCs functioning in different languages reveals an urgent need to define their insufficiently explored grammatical status. As has been highlighted above, international linguistic literature often offers nothing more than a brief description of CMCCs registered in different sentences, while specialised studies on the issue appear extremely scarce.

For example, Chevalier et al. (Chevalier, 1995) in their "Grammaire Larousse du français contemporain" offer a chapter dealing with the analysis of syntactic coordination. Although the authors do note that the traditional rule whereby coordinating conjunctions are used to unite similar elements is being disregarded in contemporary French, they fail to offer any kind of explanation as to the role of coordinating conjunctions in the given context.

Damourette and Pichon (1970) illustrate this peculiarity of the French language using the coordinating conjunction et as an example and emphasise two cases of its functional operation: in cases where the connected sentence parts perform the same syntactic function (Type 1); in cases where et unites components performing different syntactic functions (Type 2). Having analysed the French press, the authors conclude that Type 2 constructions fully comply with the language norm.

According to Delatour et al. (Delatour, 2004), coordinating conjunctions are mainly used to connect elements belonging to the same class and performing identical syntactic functions. This stipulation suggests a wider scope of application for coordinating conjunctions.

The most comprehensive and detailed account of CMCCs can be found in "La coordination en français"- a fundamental work by Antoine (Antoine, 1962), who characterised his study as an attempt to investigate a "quasi-unexplored realm of research". Analysing the existing coordinating structures registered in the French language, the author touches upon synthesis as a phenomenon of contemporary syntax, and considers zeugmatic constructions as a type of synthesis. The underlying motive behind his interest towards zeugma has to do with the reduction of one or several elements in the second part of the utterance taking place in CMCCs (which is due to the general tendency towards the economy of speech efforts).

Russian linguists suggest diverse approaches to handling the interconnection of multifunctional and homogeneous sentence parts. Researchers draw opposite conclusions depending on the way they interpret the essence of grammatical homogeneity. Contemporary linguistic literature concerned with the study of CMCCs treats them as homogeneous sentence parts, partially homogeneous or transitional (i.e., transitioning from non-homogeneous to homogeneous), and "genuine" coordination with no homogeneity (Agafonova, 2011). 
Analysing the three approaches to interpreting the grammatical nature of CMCCs, one will ultimately conclude that none of them appears explanatory enough, especially when it comes to the study of French multifunctional components united through coordination. This, in turn, brings the existing theories of CMCCs into question, challenging their capacity to reflect the very nature of coordination realised in this type of constructions.

The most widely accepted theory explaining the use of coordinating conjunctions in connecting multifunctional sentence components is the one suggesting that a coordinating conjunction acts as a secondary syntactical link, which is independent from the primary link and makes it possible to use this conjunction to unite multifunctional sentence parts (the so-called "secondary syntactic links" theory) (Mitrović \& Sauerland, 2016).

The proponents of the theory of "secondary syntactic links" address the issue of CMCCs by embracing the notion of two syntactic levels - external and internal ones. While external syntax is established through morphological-syntactical means, i.e., it is shaped on the first syntactic level (patterned operation of word forms), internal syntax is associated with the functioning of syntactic means proper (the second syntactic level) (May \& Koster, 2016).

Organisation of linking relations registered in conjunctional constructions of this type was comprehensively studied by Priyatkina (Priyatkina, 2007):

$\begin{array}{llllll}\mathrm{OH} & \text { скоро } & \text { вернулся, } & \text { но } & \text { без } & \text { куртки. } \\ \mathrm{He} & \text { soon } & \text { returned, } & \text { but } & \text { without } & \text { jacket }\end{array}$

'He soon returned, but had no jacket.' (Priyatkina, 2007)

With this example, the author illustrates the disjointed nature of these links, whereby the first link presents weak government without the conjunction но ('but'), and the second link does not require any kind of government whatsoever. The first connection-primary-is constructed through word forms, while the other-secondary-uses the conjunction. Pryatkina (Priyatkina, 2007, p. 135) believes that the secondary conjunctional link reveals itself as construed on the level of word forms, regardless of the conjunction. Pursuant to this theory, the conjunction does not modify, dismiss or transform the syntactical relations established within the word forms, but adds another dimension to them, which specific meaning is manifested in the conjunction.

This inference, however, doesn't strike as plausible. The thing is that due to its conventional syntactical independence, the conjunctional component acquires greater semantic load compared to the conjunction-free component. In most cases, the conjunctional component does not only transform the entire semantic load of the construction, but actually appears stylistically marked.

\begin{tabular}{|c|c|c|c|}
\hline L'économie & allemande & $\mathrm{a}$ & certes \\
\hline The economy & German & has & certainly \\
\hline \multicolumn{4}{|c|}{ 'The German economy has certainly benefited from the } \\
\hline réformes & de & Gerard & Schröder, \\
\hline reforms & of & Gerard & Schröder, \\
\hline \multicolumn{4}{|c|}{ reforms of Gerard Schröder, but the } \\
\hline modèle & allemand & $\mathrm{a}$ & des \\
\hline model & German & has & the \\
\hline \multicolumn{4}{|c|}{ German model has } \\
\hline plus & profondes & et & anciennes. \\
\hline more & deep & and & old \\
\hline
\end{tabular}

In this example, the second part is stylistically marked because of the conjunction mais. Should this same construction lose the conjunction, it would appear stylistically neutral. Therefore, the difference between conjunctional and non-conjunctional constructions happens to be a crucial aspect in terms of both syntactic and semantic reference. This distinctiveness of the conjunctional component defeats the purpose of syntactical links within the CMCCs. If anything, a more appropriate inquiry would concern the special connection existing within the structure under study. 


\section{Method}

\subsection{Material Studied}

As global news from the sphere of economy, business and business communication in one way or another affect all the inhabitants of the planet, it is the business vocabulary that represents the greatest interest. Saturation of the information field of human activity promotes the popularization of business vocabulary, which is becoming more accessible to the broad public. A significant role in the penetration of business vocabulary into the language of everyday communication is played by the media.

The materials for the present work were articles from the most authoritative business newspapers and magazines.

\subsection{Study Methods}

The study is based on linguistic material obtained as a result of a continuous sampling method of modern business periodicals. Online versions of newspapers and magazines, data of dictionaries were involved in the analysis. In total, about 100 examples were analyzed.

Linguistic methods such as discursive and contextual analysis, structural-semantic, descriptive method, elements of distributional analysis and transformation techniques were used.

\section{Results}

\subsection{Constructions Featuring Multifunctional Coordinating Components: Structural and Semantic Characteristics}

At the present stage, none of the interpretations of CMCCs have been proved exhaustive, which brings into question the very validity of the existing approaches devised to define this type of constructions and describe the nature of coordination they rely on. Broadly speaking, CMCCs can be referred to as a type of coordinating constructions, which specific feature lies in the inventory of multifunctional components in need of coordination. In order to disclose the essence of CMCCs, it is imperative to consider two key factors: the semantic-syntactical nature of coordinating conjunctions; and the differences within the coordinating constructions proper.

In CMCCs, the core component of the construction is represented by the coordinating conjunction, which functions as not only the glue connecting sentence parts, but also as an indicator of the secondary conjunctional component. Haff (Haff, 1990) defines CMCCs as emphaticised as opposed to non-emphaticised non-conjunctional constructions. Thus, in "Je veux des pommes mais rouges" the coordinating conjunction mais specifies object feature, as in "I don't just want apples, but red apples specifically". Such construction is marked stylistically and emotionally as compared to its non-conjunctional (i.e., neutral) counterpart: "Je veux des pommes rouges".

In other words, multifunctional sentence components respond to the eliminated coordination in a number of ways: the meaning of the utterance changes to a certain degree, thus shifting the original semantic focus; expressivity and emotional colouring of the utterance end up reduced; and sentence structure is made somewhat "heavier", especially in cases where conjunctional components are expressed by full word collocations.

The increase in the strength and audible duration of conjunctions is primarily achieved through pausing. The component introduced by the coordinating conjunction is typically marked by intonation. In most cases, it also stands out being separated by a comma. In some instances, the secondary conjunctional component is isolated from the first part of the sentence with a dash or a colon:

$$
\begin{array}{lllllll}
\text { La question, } & \text { sensible, } & \text { de } & \text { la } & \text { présence } & \text { de } & \text { caméras } \\
\text { The question, } & \text { sensitive, } & \text { of } & \text { the } & \text { presence } & \text { of } & \text { cameras }
\end{array}
$$

'The sensitive question of the presence of cameras

$\begin{array}{llllllll}\text { en } & \text { garde } & \text { à } & \text { vue }- & \text { et } & \text { dance } & l e & \begin{array}{l}\text { cabinet } \\ \text { office }\end{array} \\ \text { in } & \text { custody } & \text { at } & \text { view }- & \text { and } & \text { in } & \text { the } \\ \text { in custody }- \text { and in the } & & & & & \\ d u \quad \text { juge }- & \text { n'est } & \text { pas } & \text { encore } & \text { tranchée. } & \\ \text { of } & \text { judge }- & \text { is } & \text { not } & \text { yet } & \text { decided } & \end{array}$

judge's office - is not yet decided.' (Piel \& Tilouine, 2018)

Graphic characters can in this case be viewed as immediate sings of a specific syntactical meaning: in theory, a character is estimated through its conformity with the intonation. However, an actual speaker (or for the purposes 
of this particular example - an actual writer) resorts to such characters to frame up the utterance. Such examples are of particular interest, because in this case semantically remote non-homogeneous components are separated from one another by a dash, which is viewed as a rather prominent punctuation mark. Thus, they are segregated by a lengthy pause that accentuates the semantic distance between them. The dash does not function as an isolating element, but rather emphasises the significant role of the component introduced by the conjunction, making it the core element in the utterance. In such cases, the secondary conjunctional component is closely connected with the entire utterance and bears full informative load:

$\begin{array}{llllll}\text { (6) Il arrive } & \text { que } & \text { les } & \text { États-Unis } & \text { réunissent }- \\ \text { the happen } & \text { that } & \text { the } & \text { United States } & \text { reunite } \\ \text { 'It happens that the Unites States reunited - } & & & \\ \text { et parfois } & \text { involontairement }- & \text { à } & \text { fragiliser } & \text { l'Iran. } \\ \text { and sometimes } & \text { involuntarily - } & \text { to } & \text { weaken } & \text { Iran. }\end{array}$

and sometimes involuntarily - to weaken Iran.' (Doutrebente, 2018)

Syntactic constructions featuring multifunctional sentence components, which are connected through explicitly expressed coordination, cannot be considered a sub-type of constructions with homogeneous sentence parts, because they violate the homogeneity criterion. The difference between CMCCs and the corresponding non-conjunctional constructions becomes evident against the background of a set of indicators: at the syntactical level, the component introduced by the coordinating conjunction acquires greater independence, which, in turn, weakens subordination; at the semantic level, it is the secondary (conjunctional) component that embeds meaningfully essential information; at the stylistic level, the component introduced by the coordinating conjunction typically acquires expressive marking, which testifies to its stylistic importance.

\subsection{Sentence Types and Constructions Typology}

One of the distinctive features of English syntax is that it features secondary predicative conjunctional structures, i.e. word combinations, which components are linked through predicative syntactical connection.

At the present stage of its development, linguistic science investigates some specific issues and controversial problems associated with composite sentences. The two constituting parts of a composite sentence are traditionally defined as a main clause and a dependent clause. However, the very opposition of main vs dependent is rendered impossible, if the dependent clause functions as a subject or a predicate.

There is a range of supra-phrasal units, which status falls in between compound and complex sentences. For example, thanks to it far-reaching semantics, while can be viewed as both a coordinative link and a compound link depending on the context:

(7) Industrial stocks tumbled 4.5 percent while the aluminum maker Arconic fell 8.9 percent after its earnings failed to impress investors (Phillips, 2018).

Composite sentences with a connective pronoun which can technically be viewed as sentences featuring an attributive predicative clause, yet the predicative here does not refer to a single word, but to the entire main clause. Thus, the "dependent" part acquires greater independence. For example:

(8) The strong job reports last week fuelled hopes that wage growth would follow which could lead to higher inflation, creating new challenges for the central bank to manage (Phillips, 2018).

The same is true for sentences featuring the conjunction when in a non-temporal meaning:

When giving a speech during Monday's sell-off, Mr. Trump made no mention of stocks (Phillips, 2018).

Simple sentences with secondary predication are an intermediate type of sentences taking their place between simple sentences proper (non-expanded) and composite sentences (expanded). Expanded sentences technically comprise a single grammatical basis (a subject and a predicate) and can easily be transformed into two simple ones. Such transformation can prove useful in identifying predicative word groups:

(10) Whatever the government's justification for nationalization, the fact is that state-controlled enterprises are rife with inefficiencies, and operate through incentive systems that breed corruption (Sonin, 2018).

Other types of expanded sentences include sentences with homogeneous parts (featuring only one predicative link, while the other one somewhat merges with the first one): 
a. He stood up and left [He stood up. He laughed].

b. Tom and Mary went home [Tom went home. Mary went home].

Sentences with a subordinate member introduced by conjunctions than, as tough, but:

a. He tried to persuade her, but in vain [it was in vain].

b. She is prettier than you [than you are].

Sentences with a detached element:

He looked at her face — pale and distorted [He looked at her face, which was pale and distorted].

A simple sentence can be expanded in a number of ways, with new ones evolving continuously. In terms of its saturation with logical content and the intricacy of its inherent semantic relations, a simple sentence can be on a par with its both complex and expanded counterparts.

For a contemporary language, CMCCs can be extremely instrumental in expanding the elementary sentence structure. For the purposes of this paper, the following two conjunctional links can be differentiated: conjunctions connecting words correlated as dominant vs independent; and conjunctions connecting words that do not present homogeneous word parts, but take a parallel syntactic position in a sentence. Therewith, word forms can be arranged following the patterns established at the first level of syntactic relations.

In Type 1 constructions, the first component acts as a dominant word, while the dependent word form bearing objective or adverbial meaning follows the predicate verb (predicate + coordinating conjunction + adverbial modifier/object).

In contemporary French, utterances featuring a predicate and an adverbial modifier connected by coordination are prevailing (they account for about $87.5 \%$ of all collocations with coordinated principal and subordinate sentence parts). For example:

$\begin{array}{lllllllll}\text { (14) Je } & \text { suis } & \text { économe, } & \text { mais } & \text { pas } & \text { à } & \text { ce } & \text { point- } & \text { là } \\ & \text { I } & \text { am } & \text { economical, } & \text { but } & \text { not } & \text { at } & \text { that } & \text { point }\end{array}$

'I am thrifty, but not that much.'

In Russian, such constructions commonly use simple coordinating conjunctions like $u$, но, $\partial a, a$; in English - but, and, thus; in French-mais, et.

Following the study of simple adversative conjunctions used in the three languages within different combinations of predicates and adverbial modifiers, we can single out five general logical-semantic models: utterances bearing the meaning of concession; utterances bearing the meaning of cause; utterances bearing the meaning of lack of efficiency; utterances bearing the meaning of discrepancy; and utterances bearing the meaning of restriction.

In Type 2 constructions, the first component is a dependent word. A study of syntactic functions fulfilled by multifunctional components of this kind allowed to single out several types of word forms, where two multifunctional subordinate sentence parts are connected by a coordinating conjunction:

1) a word form with objective of adverbial meaning refers to the predicate verb:

- predicate verb + adverbial modifier + coordinating conjunction + adverbial modifier (with different specific functions);

- predicate verb + object + coordinating conjunction + adverbial modifier;

- predicate verb + object + coordinating conjunction + attribute.

In Russian, the most frequently used conjunctions include но, хотя, если; in English-but, thus, and; in French — et, mais, disjointed conjunction non seulement ... mais.

2) the dependent word-form acting as an attribute refers to the substantive member: substantive member + attribute + coordinating conjunction + adverbial modifier.

In Russian, such constructions commonly use the conjunctions like но and хотя; in English - but and although; in French-mais and et. With constructions "substantive member + attribute + coordinating conjunction + adverbial modifier", the attribute can only be in postposition. A distinctive feature of the attribute is that its formalisation depends on the content of the syntactic group it belongs to. Constructions "substantive member + attribute + coordinating conjunction + adverbial modifier" can enclose any kind of attribute. It would be fair to assume that the conjunction singles out the attributes expressing quality and features that are not actually 
inherent in the attribute, but are of importance in the given context. In this case, the coordinating conjunction amplifies the expressive and impressive potential of the attribute, entrusting it with meaningful and emotional load, making it more presentative, vivid and emotional.

According to research findings, the internal emotional pause occurs whenever resultative relations appear sudden or inconsistent. Audible pause emerges either prior to the coordinating conjunction, or in its wake.

Contemporary linguistic literature has on many occasions noted a characteristic feature of modern syntax actualisation of sentence parts through their placement in the stressed position. Studies show that the most significant elements of the utterance, fulfilling various functions within the sentence, are most commonly shifted to the end of the sentence. Linguists attribute this phenomenon to the dominance of spoken language, whereby the patterns of word placement appear more flexible as compared to the practices established in the written language. As a natural result, the flexible patterns penetrate the literary language.

\subsection{Constructive Functions of CMCCs}

It is conceivable that $\mathrm{CMCCs}$ emerged in the speech process and were gaining ground in the language over extended periods of time. In contemporary French, CMCCs are rather widespread and recurrent.

By virtue of its specifics, CMCCs used in the language of business media act as a stylistic means helping strengthen the semantic load of the utterance, make the speech more expressive and emotional. This is primarily because of the expressiveness typical of the press: while it certainly fulfils its constructive function, it at the same time gravitates towards growing tension and increased expressive and emotional saturation. This stipulation can be exemplified by material retrieved from various sources:

(15) Global debt ratios have risen sharply since the financial crisis began, while traditional lenders' margins have been squeezed... (Sonin, 2018).

$\begin{array}{lllll}\text { Les choses ont } & \text { été } & \text { dites, } & \text { mais } \\ \text { The things have } & \text { be } & \text { say, } & \text { but } \\ \text { 'Things have been said, but without } & & & \\ \text { esprit de } \quad \text { confrontation, } & \text { précisait } & \text { un } & \text { diplomate. } \\ \text { mind of } & \text { confrontation, } & \text { stated } & \text { a } & \text { diplimat }\end{array}$

the spirit of confrontation, said a diplomat.' (Doutrebente, 2018)

(17) Greek tourism hit by recession but still seen as recovery hope (Smith, 2011).

(18) A zero-hours contract is not "flexibility" but exploitation - and it's rising (Elliot, 2016).

CMCCs can fulfil various functions, including adjunction (supplementation, expansion of content):

По

According

данным

data

Всемирного

World

банка,

Bank,

доля

'According to the World Bank, the proportion

$\begin{array}{lllll}\text { чиновников } & \text { по } & \text { отношению } & \text { к } & \text { численности } \\ \text { officials } & \text { according } & \text { relation } & \text { to } & \text { number }\end{array}$

of officials in relation to the

$\begin{array}{lllll}\text { населения } & \text { в } & \text { нашей } & \text { стране } & \text { составляет } \\ \text { population } & \text { in } & \text { our } & \text { country } & \text { constitutes }\end{array}$

population in our country is

less one percent,

less than one percent, which is significantly

$\begin{array}{lllll}\text { меньше, } & \text { чем } & \text { в } & \text { развитых } & \text { странах. } \\ \text { lower, } & \text { than } & \text { in } & \text { developed } & \text { countries }\end{array}$

lower, than in developed countries.' (Matveychev, 2010)

Limitation (differentiation): 


$\begin{array}{lllll}\text { Санкции } & \text { затруднили } & \text { развитие } & \text { страны, } & \text { но } \\ \text { Sanctions } & \text { hampered } & \text { development } & \text { country, } & \text { but }\end{array}$

'Sanctions have hampered the development of the country, but

$\begin{array}{lllll}\text { в } & \text { то } & \text { же } & \text { время } & \text { стали } \\ \text { in } & \text { that } & \text { same } & \text { time } & \text { became }\end{array}$

at the same time have become

$\begin{array}{llll}\text { стимулом } & \text { для } & \text { обновления } & \text { экономики. } \\ \text { incentive } & \text { for } & \text { renewal } & \text { economy }\end{array}$

an incentive for economic renewal.' (Maksimova, 2015)

Explanation (specification, emphasis):

\begin{tabular}{|c|c|c|c|c|}
\hline $\begin{array}{l}\text { Ho } \\
\text { But }\end{array}$ & $\begin{array}{l}\text { тот } \\
\text { that }\end{array}$ & $\begin{array}{l}\text { проект, } \\
\text { project, }\end{array}$ & $\begin{array}{l}\text { который } \\
\text { which }\end{array}$ & $\begin{array}{l}\text { предстоит } \\
\text { to be }\end{array}$ \\
\hline \multicolumn{5}{|c|}{ But the project to be } \\
\hline разработать & и & осуществить, & не & имеет \\
\hline develop & and & implement, & not & has \\
\hline \multicolumn{5}{|c|}{ developed and implemented has no } \\
\hline аналогов & не & только & в & истории \\
\hline counterparts & not & only & in & history \\
\hline \multicolumn{5}{|c|}{ counterparts in the history of not only } \\
\hline России, & но & и & других & стран. \\
\hline Russia, & but & and & other & countries \\
\hline
\end{tabular}

Russia, but other countries as well.' (Abdullaev, 2009)

Stipulation:

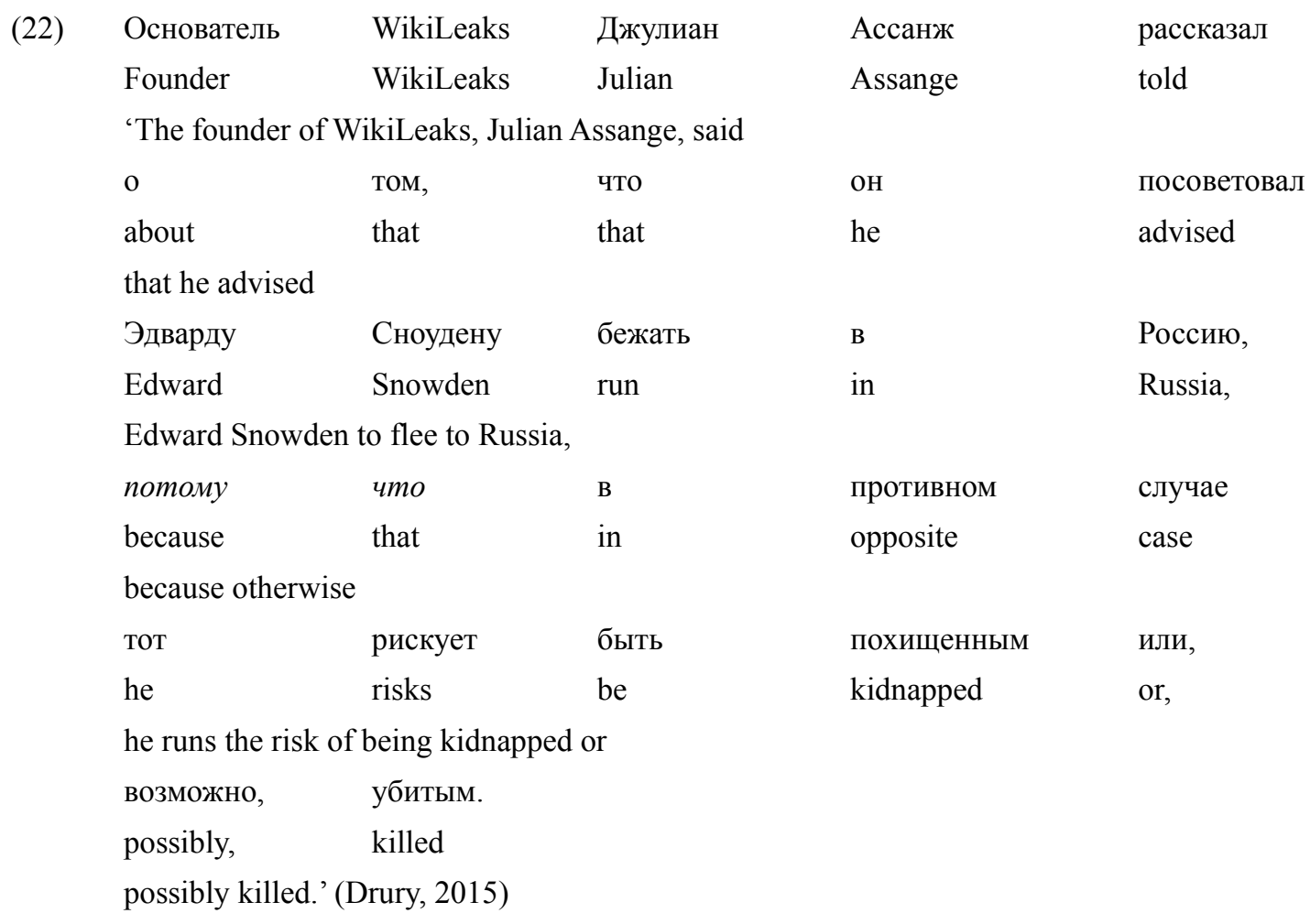

Notably, the sentence part singled out via the coordinating conjunction acquires specific emotional content, ensuring that communicating parties pay due attention to certain details present in the message. Only an in-depth 
functional-semantic analysis of the coordinating conjunction as a linking means used in various types of CMCCs will ultimately highlight the complex logical-semantic relations that can be established within them.

\section{Conclusion}

After presenting the results, you are in a position to evaluate and interpret their implications, especially with Linguistic identity refers to a person's self-identification with the corresponding culture, his or her belonging to a certain language group. Linguistic identity may change throughout a person's lifetime influenced by his or her activity - including professional activity. Syntax can be viewed as one of the means through which linguistic identity gets actualised in speech or text. Used in the framework of professional communication, syntactic constructions featuring multifunctional components in many ways empower the speaker to realise his or her linguistic identity.

CMCCs are defined as syntactic constructions, in which the coordinating conjunction connects words fulfilling different syntactic functions (adjunction, limitation, concession, explanation, stipulation) and rendering specific emotional content that makes communicating parties focus on certain details present in the message. This, in turn, may play a decisive role in the framework of professional communication.

The structure of professional identity of a business person comprises verbal-semantic, thesaurus, and motivational levels. Recreating this structure will require a comprehensive analysis of all aspects intrinsic to the linguistic identity of a business person operating in the context of professional interaction, which calls for the study of linguistic phenomena revealing the multidimensional and varied nature of relations established between language and identity.

At the same time, the increasing interest in the issues of syntactic coordination means that a wide variety of coordinating constructions are being researched, including those that deviate from the traditional canons of coordination. Among them are syntactic constructions featuring multifunctional coordinating components that serve as an indicative example of the sheer capacity of coordination as a syntactical phenomenon.

The presence of a coherent coordinating link that connects words performing different syntactic functions in a sentence is evidenced by their coordinative coupling. This application of the coordinating conjunction goes beyond its traditional use, which implies the realization of a connection between some homogeneous entities - components of a complex sentence and homogeneous members of a simple sentence. The study showed that syntactic constructions featuring multifunctional coordinating components are characterised by wide and regular reproducibility and have a fairly wide distribution in modern European languages.

At the same time, the conjunctional component in most cases acquires a distinctly expressed stylistic colouring. It is no coincidence that some scholars characterise coordinative constructions featuring conjunctions as more emphatic compared to their more neutral counterparts not accompanied by conjunctive elements.

The study of syntactic constructions featuring multifunctional coordinating components was based on a number of parameters: the set of tools used in these constructions and the features of their functioning; the semantics and realisation of the components making up such constructions. The study showed that as far as syntactic constructions featuring multifunctional coordinating components are concerned, their specifics is manifested not only in the set of coordinating means, but also in the peculiarities of their functioning.

\section{Acknowledgments}

The publication has been prepared with the support of the "RUDN University Program 5-100".

\section{References}

Abdullaev, R. (2009). U Rossii velikoye $i$ svetloye budushcheye [Russia has a great and bright future]. Retrieved February 12, 2019, fromhttps://fundamental-economic.uz/article/y-россии-великое-и-светлое-будущее

Agafonova, I. (2011). On syntax, alternative semantics, and computation in coordination. East Lansing, MI: Michigan State University.

Aleksandrova, O. V., Mendzheritskaya, E. O., \& Malakhova, V. L. (2017). Dynamic changes in modern English discourse. Training Language and Culture, 1(1), 100-117. Retrieved March 10, 2019, from http://rudn.tlcjournal.org/archive/1(1)/1(1).pdf

Bradley, D., \& Bradley M. (2013). Language attitudes: The key factor in language maintenance. In B. David \& B. Maya (Eds.), Language endangerment and language maintenance: An active approach (pp. 21-30). Routledge. https://doi.org/10.4324/9781315028811

Bright, W. (2017). Social factors in language change. In C. Florian (Ed.), The handbook of sociolinguistics (pp. 
81-91). Wiley-Blackwell.

Chevalier, J.-C., Benveniste, C.-B., Arrivé, M., \& Peytard, J. (1995). Grammaire Larousse du français contemporain. Paris: Larousse.

Crystal, D. (2017). My priority for the next 50 years: an online cultural dictionary. Training Language and Culture, 1(1), 14-27. https://doi.org/10.29366/2017tlc.1.1.1

Curau, L. (2012). Pourquoi l'économie allemande est-elle si puissante? [Why is the German economy so powerful?]. $\quad$ Retrieved $\quad$ February $12, \quad 2019, \quad$ from https://www.cafedelabourse.com/dossiers/article/economie-allemande

Damourette, J., \& Pichon, E. (1970). Des mots à la pensée: essai de grammaire de la langue française [Words to thought: French language grammar test]. Paris: D'Artrey.

Delatour, Y., Jennepin, D., Dufour, M. L., \& Teyssier, B. (2004). Nouvelle grammaire du français. Paris: Hachette Livre.

Derounian, J. (2013). There might be a housing crisis - but it's not in my back yard. Retrieved February 12, 2019, from https://www.theguardian.com/housing-network/2013/feb/25/housing-crisis-is-not-in-my-back-yard

Doutrebente, L. (2018). Les sanctions vont-elles mettre l'Iran à genoux? 2019 sera crucial! [Will sanctions put Iran on its knees? 2019 will be crucial!]. Retrieved February 12, 2019, from https://fr.sputniknews.com/international/201808301037872915-iran-sanctions-usa-france/

Drury, F. (2015). Assanzh: Ya posovetoval Snoudenu bezhat'v Rossiyu [Assange: I advised Snowden to flee to Russia]. Retrieved February 12, 2019, from https://inosmi.ru/world/20150831/229964750.html

Elliot, L. (2016). A zero-hours contract is not "flexibility" but exploitation - and it's rising Retrieved February 12 , 2019 , from https://www.theguardian.com/business/2016/mar/09/zero-hour-contract-is-not-flexiblity-but-exploitation-an d-its-rising

Gérald, A. (1962). La coordination en français. Paris: D’Artrey.

Gregory, M., \& Carroll, S. (2018). Language and situation: Language varieties and their social contexts. Routledge. https://doi.org/10.4324/9780429436185

Haff, M. H. (1990). Coordonnants et éléments coordonnés: une étude sur la coordination en français moderne. L'information Grammaticale, 46(1), 17-21. https://doi.org/10.3406/igram.1990.1936

Maksimova, R. (2015). Putin: pik negativnykh posledstviy ot sanktsiy Zapada proyden [Putin: the peak of the negative effects from Western sanctions has been passed]. Retrieved February 12, 2019, from https://www.tvc.ru/news/show/id/67144

Malyuga, E. N., \& Tomalin, B. (2017). Speech Behavior in Business Communication: A Linguacultural Perspective (Book 3, vol. 2, 961-968). 4th International Multidisciplinary Scientific Conference on Social Sciences and Arts SGEM 2017, www.sgemsocial.org, SGEM2017 Conference Proceedings, Albena (Bulgaria).

Matveychev, O. (2010). Mif ob izbytke chinovnikov v Rossii [The myth of redundant public officials in Russia]. Retrieved February 12, 2019, from https://matveychev-oleg.livejournal.com/18658.html

May, R., \& Koster, J. (eds.). (2016). Levels of syntactic representation (Vol. 10). Walter de Gruyter GmbH \& Co KG.

McGee, P. (2018). Vague language. Training Language and Culture, 2(2), 40-54. https://doi.org/10.29366/2018tlc.2.2.3

Mitrović, M., \& Sauerland, U. (2016). Two conjunctions are better than one. Acta Linguistica Hungarica, 63(4), 471-494. https://doi.org/10.1556/064.2016.63.4.5

Piel, P. S., \& Tilouine, J. (2018). Financement libyen de la campagne de 2007: Nicolas Sarkozy en garde à vue [Libyan financing of the 2007 campaign: Nicolas Sarkozy in custody]. Retrieved February 12, 2019, from https://www.lemonde.fr/police-justice/article/2018/03/20/financement-libyen-de-la-campagne-de-2007-nico las-sarkozy-en-garde-a-vue_5273446_1653578.html

Phillips, M. (2018). Dow Jones and S.\&P. slide again, dropping by more than 4\%. Retrieved February 12, 2019, from

https://www.nytimes.com/2018/02/05/business/stocks-equities-dow-markets.html?action=click\&module=T 
op $\% 20$ Stories\&pgtype $=$ Homepage

Ponomarenko, E. V. (2018). Factors of business English functional efficiency (Vol. 5 Science \& Society, issue 3.6 Language \& Linguistics, 209-216). 5th International Multidisciplinary Scientific Conference on Social Sciences and Arts SGEM 2018, www.sgemsocial.org, SGEM2018 Conference Proceedings, 26 August-1 September 2018, Albena (Bulgaria). https://doi.org/10.5593/sgemsocial2018/3.6/S14.028

Priyatkina, A. F. (2007). Russkiy sintaksis v grammaticheskom aspekte: Sintaksicheskiye svyazi i konstruktsii [The grammatical aspect of Russian syntax: Syntactical links and conscructions]. Vladivostok: Far East University Press.

Roberts, S., \& Winters, J. (2012). Social structure and language structure: The new nomothetic approach. Psychology of Language and Communication, 16(2), 89-112. https://doi.org/10.2478/v10057-012-0008-6

Smith, C. H. (2018). L'économie va bien, mais à quel prix? [The economy is good, but at what cost?]. Retrieved February 12, 2019, from https://planetes360.fr/leconomie-va-bien-a-prix/

Smith, H. (2011). Greek tourism hit by recession but still seen as recovery hope. Retrieved February 12, 2019, from https://www.theguardian.com/world/2011/aug/04/greek-tourism-recession-recovery-hope

Sonin, K. (2018). Russia's economic stagnation is here to stay. Retrieved February 12, 2019, from https://www.project-syndicate.org/commentary/russia-economic-stagnation-structural-reform-by-konstantin -sonin-2018-02?barrier=accesspaylog

Vishnyakova, O. D., \& Polyakova, N. V. (2017). Linguistic and functional cognitive peculiarities of media language as the basis of interpretations in the communicative sphere. Training Language and Culture, 1(2), 86-101. https://doi.org/10.29366/2017tlc.1.2.6

\section{Copyrights}

Copyright for this article is retained by the author, with first publication rights granted to the journal.

This is an open-access article distributed under the terms and conditions of the Creative Commons Attribution license (http://creativecommons.org/licenses/by/4.0/). 